


\section{About IJMA [last updated October, $\left.1^{\text {st }}, 2021\right]$}

$\checkmark$ International Journal of Medical Arts is the Official Journal of the Damietta Faculty of Medicine, AlAzhar University, Egypt

$\checkmark$ It is an International, Open Access, Double-blind, Peer-reviewed Journal

$\checkmark$ Published four times a year

$\checkmark$ The First Issue was published in July 2019

$\checkmark$ Published under the following license: Creative Commons Attribution-ShareAlike 4.0 International Public License (CC BY-SA 4.0). It had updated from the Creative Commons license [CC BY] in volume 2, Issue 4, October 2020 About IJMA

$\checkmark$ The Egyptian Knowledge Bank hosts the web site of IJMA

$\checkmark$ The Egyptian Knowledge Bank supports IJMA

$\checkmark$ IJMA follows the regulations of the International Committee of Medical Journal Editors

$\checkmark$ IJMA is indexed in the "Directory of Open Access Journals" [15 January 2021].

$\checkmark$ IJMA is indexed in J-Gate [29-6-2021]

$\checkmark$ IJMA is a member of the International Society of Managing and Technical Editors

$\checkmark$ Listed in "Index Copernicus", "Publons", "Academic resource index [ResearchBib]" "Electronics journal library", "Eurasian Scientific Journal Index", "WorldCat" Superstar Journal Database, and "Citefactor"

$\checkmark$ IJMA introduced to the search engine [BASE] through DOAJ

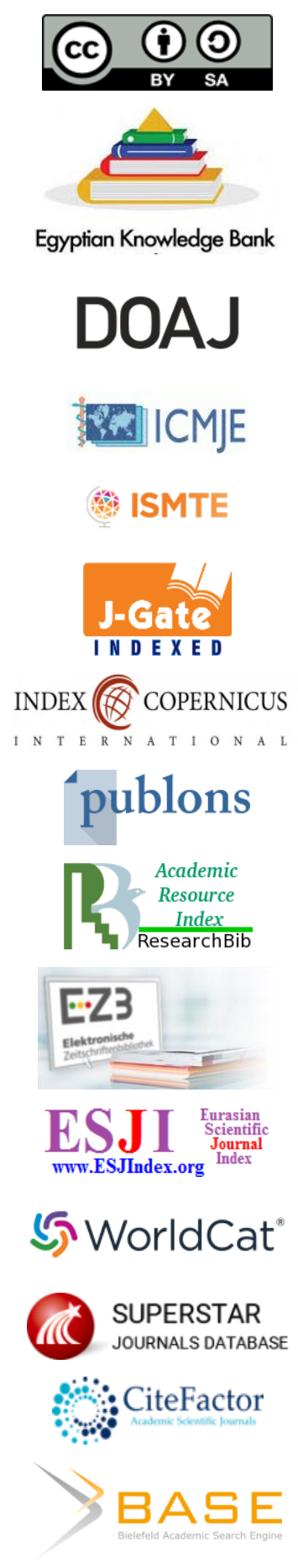




Available online at Journal Website
https://ijma.journals.ekb.eg/
Main subject [Radiology]

Original Article

\title{
Ultrasonographic Evaluation of Fetal Brain Midline Structures in The Second Trimester: The role of 2D versus 4D, with post-natal correlation
}

\author{
Ahmed Bedeir Abd El Salam [1], Faisal Ali Mustafa [2], Zainab Shehata Sayed [2]; Hamada Mohamed Abuelmatti [3]
}

1 Department of Radiodiagnostics, Damietta Faculty of Medicine, Al-Azhar University, Egypt
2 Department of Obstetrics and Gynecology, Faculty of Medicine, Al-Azhar University, Assiut, Egypt
${ }^{3}$ Department of Obstetrics and Gynecology, Damietta Faculty of Medicine, Al-Azhar University, Egypt

Corresponding author: Ahmed Bedeir Abd El Salam

Email: semsmahmed2007@yahoo.com

Submission date: August 20, 2021; Acceptance date: September 30, 2021

DOI: $10.21608 / \mathrm{ijm}$.2021.200543

\section{ABSTRACT}

Background: Midline cerebral structures are essential for the normal morphogenesis and function of the fetal brain. However, the diagnosis of congenital anomalies of midline cerebral structures.

The Aim of The Work: This study aimed to evaluate the role of 2D versus 4D ultrasound in the diagnosis of midline structures of the fetal brain at the second trimester of pregnancy.

Patients and Methods: 200 pregnant women at the second trimester [18-22 weeks] were selected. They were clinically evaluated to check the female and fetal wellbeing. Then a screening of fetal brain midline strictures had been performed by two- and four-dimensional ultrasound, aiming to discover any anomalies of the fetal brain midline structure. Both scans were compared with the postnatal transcranial ultrasound.

Results: The 2D ultrasound detected no abnormality in 194 out of 200 fetuses [97.0\%], and 4 cases [2.0\%] had mega-cisterna magna, and 2 cases [1.0\%] had encephalomylocele, which were detected by the $4 \mathrm{D}$ and confirmed by postnatal transcranial ultrasound. The 4 D US discovered 2 cases [1.0\%] of Dandywalker malformation, which was confirmed by postnatal transcranial US. There was a complete agreement between prenatal $4 \mathrm{D}$ ultrasound and postnatal transcranial ultrasound. The prenatal 2D ultrasound had a sensitivity of $75.0 \%$, specificity of $100.0 \%$, PPV of $100.0 \%$, NPV of $98.7 \%$ and overall accuracy of $99.0 \%$. Otherwise, the prenatal $4 \mathrm{D}$ ultrasound was $100.0 \%$ sensitive and specific.

Conclusion: 4D ultrasound showed superiority in the diagnosis and confirmation of the fetal brain midline structure's abnormalities. Also, the prenatal 4D ultrasound was $100.0 \%$ sensitive as postnatal transcranial US.

Keywords: Two-Dimensional; Four-Dimensional; Fetal Brain Midline Structures; Postnatal; Transcranial Ultrasound.

This is an open-access article registered under the Creative Commons, ShareAlike 4.0 International license [CC BY-SA 4.0] [https://creativecommons.org/licenses/by-sa/4.0/legalcode.

Citation: Abd El Salam AB, Mustafa FA, Sayed ZS, Abuelmatti HM. Ultrasonographic Evaluation of Fetal Brain Midline Structures in The Second Trimester: The role of 2D versus 4D, with post-natal correlation. IJMA 2021; 3 [4] October-December: 1811-1817. [DOI: 10.21608/ijma.2021.200543].

${ }^{*}$ Main subject and any subcategories have been classified according to the research topic 


\section{INTRODUCTION}

Fetal malformations are associated with increased risk of newborn disability. If fetal malformations diagnosed early in pregnancy, it helps the decision of whether or not to terminate the pregnancy. Thus, regular prenatal screening is the key to decrease the rate of newborns' disability ${ }^{[1]}$. The reduction of malformed fetus improves the quality of the newborns and promote societal and family development. Thus, antenatal screening is of great value ${ }^{[2]}$.

The organogenesis of the central nervous system from the neural tube begins early in the intrauterine life, and passes through a series of processes of differentiation until after birth [3]. The nervous elements that present in the midline cerebral structures are indispensable for the normal morphogenesis and function of the brain thus median echo should be assessed at the end of the first trimester ${ }^{[4]}$.

The diagnosis of congenital brain anomalies including the median structures is difficult during fetal life as the routinely used standard axial sonographic do not show some cerebral structures as the cerebellar vermis and corpus collosum [5]. However, in high-risk pregnancies during the first to early second trimester, the midline anomalies could be visualized [6]. The classification of midline anomalies first reported by De Meyer and later revised by Fitz et al. includes two principal classes: closure defects and diverticulation disorders ${ }^{[7,8]}$. The ontogenesis of cerebral midline occurs after the seventh week of amenorrhea recognized as ventral initiation related strictly to the development of the midface [9].

Routine ultrasound screening is an established tool of antenatal care as it represents a simple non-invasive method of great importance in routine prenatal assessment, starting point in neuroscientific studies ${ }^{[10,11]}$ as well as increased fetal brain malformations detection rate [12].

The use of a detailed morphologic ultrasound protocol permitted an increased first trimester detection rate of $69.5 \%$ major CNS malformations [13]. Visentin et al. reported their experience on the use of the transfrontal view as a novel two-dimensional [2D] method for imagining of the fetal midline cerebral structures and the facial profile [14].

$4 \mathrm{D}$ ultrasound has been presented to the medical practice and played a complementary role to $2 \mathrm{D}$ and $3 \mathrm{D}$ ultrasound provision of real time images. 4D ultrasound allows visualization of embryonic movements two weeks earlier than 2D ultrasound [15] and have given the opportunity to explicit detail fetal anatomy and fetal activity [16]. However, 4D mainly used to assess fetal behaviour, but Öcal et al. [17] used it to evaluate different fetal malformations and concluded that, it may be used as a complementary instrument for fetal congenital malformation assessment, especially congenital anomalies of the face, spine, extremity, and abdominal wall. In high-risk fetuses to CNS malformations or in suspicious cases on basic examination, the fetal neurosonogram is warranted, that should be done by an expert investigator [6]. For the assessment of a satisfactory visualization of median structures, classic examination should be used in combination with modern techniques [18].

\section{THE AIM OF THE WORK}

This study was conducted to investigate the efficiency and the accuracy of the two-dimensional ultrasound versus four-dimensional ultrasound in diagnosing of the midline structures of the fetal brain at the second trimester of pregnancy [18-22 weeks] confirmed by post-natal transcranial ultrasound.

\section{PATIENTS AND METHODS}

After ethical approval from ethical committee of Obstetrics and Gynecology Department, Damietta Faculty of Medicine, and Assiut Faculty of Medicine, Al-Azhar University, an informed written approval was signed by each participant. The current work completed by 200 pregnant females during the second trimester [18-22 weeks of gestation]. The study was completed between January 2019 and June 2021. All pregnant females within the second trimester, normal and high-risk pregnancies [diabetes, hypertension, heart diseases, smoking cigarettes, drinking alcohol and using illegal drugs] and subjects having children with congenital brain anomalies were enrolled in this study. Any women refused to participate, at the first and third trimesters of pregnancy, who had twins or multiple pregnancies as well as intra-uterine fetal death, were excluded from the study.

All females were evaluated by clinical history taking and examination. Ultrasound evaluation of fetal midline structures was completed by a VoLuSON p5 device. A Curved Linear Array 2.0-5.0 MHz probe was used for 2D imaging, and a broadband volume curved ultrasound transducer of 2-6 MHz was used for 4D imaging. In each case, an attempt was made to obtain a median plane of the fetal brain with two-dimensional [2D] followed by fourdimensional [4D] ultrasonography at the same session. The transducer was aligned with the anterior fontanelle and the midline sutures by either a transvaginal approach [according to The International Society of Ultrasound in Obstetrics and Gynecology guidelines] or by a transabdominal scan when the transvaginal scan was technically difficult, or to obtain good images. All the fetal parts were assessed, beginning 
by the fetal cranium, and the findings were recorded. Visualization of the relevant anatomic details of the median plane, the corpus callosum and cerebellar vermis in particular, was noted for both 2D and 4D images. An attempt was made to visualize the main landmarks of the cerebellar vermis, namely the fastigium of the fourth ventricle and the two main fissures. The $2 \mathrm{D}$ images were obtained first by the broad band volume curved probe. Then, $4 \mathrm{D}$ volume images were obtained after creating a field box fitted to the area of interest. Both images of 2 and 4Ds were put side by side on the screen and a $4 \mathrm{D}$ image was obtained on the full screen. The volume data were acquired with the $4 \mathrm{D}$ real time option, provided that, the acquisition times were $<20 \mathrm{~s}$ per cine volume, and scan angles ranging from $30^{\circ}$ to $60^{\circ}$. Of the imaging modalities of 4D-USG, only surface rendering mode [SRM] was used. The mean duration of each examination was $25 \mathrm{~min}$ [20-30 min]. However, no time limit was set before the anomaly scan. Cephalocele was defined as a neural tube defect characterized by protrusions of intracranial structures [the brain tissue] through a defect in the skull. In axial view, it was recognized as a cystic cranial lesion in continuity with the brain [Figure 1]. On the other side, Mega cisterna magna characterized by a true enlarged retro and infracerebellar CSF space [the space between the inferior margin of the vermis and the posterior rim of the foramen magnum] [Figure 2].

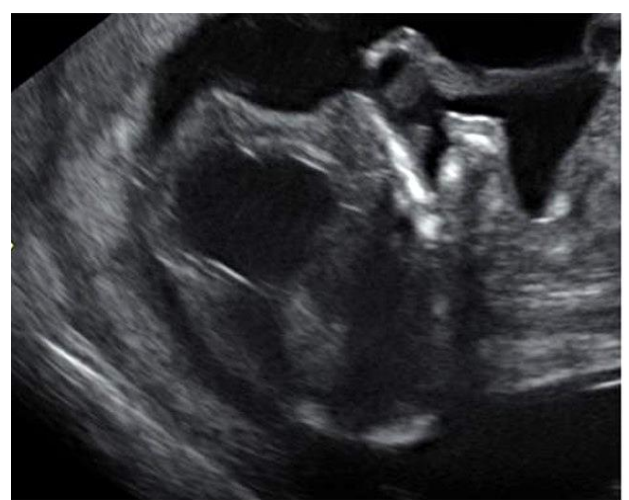

Figure [1]: Axial view of the fetal brain showed a cystic cranial lesion in continuity with the brain can [most probably encephalocele]

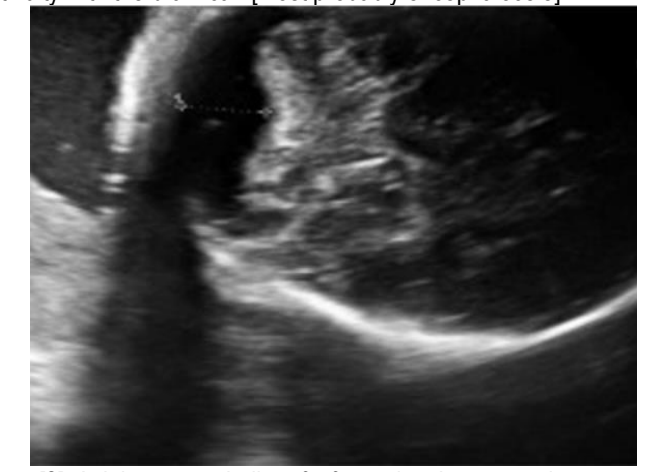

Figure [2]: Axial transcerebellar of a fetus showing mega cisterna magna.
Post-natal transcranial ultrasound was done for all newborns and used as the reference tool to ensure the efficiency of 2D and 4D ultrasound diagnosis.

\section{Statistical analysis:}

The data was anonymized and fed to Microsoft Excel, version 2016 [Microsoft Inc., USA]. Percentages were calculated for categorical data and diagnostic indicators of each modality were calculated manually from the following equations.

- Sensitivity = true positive [TP]/[true positive + false negative [FN]].

- Specificity = true negative [TN]/[true negative + false positive [FP]].

- Positive predictive value [PPV] = TP/[TP+FP]

- Negative Predictive value [NPV] = TN/[TN+FN];

- Overall Accuracy=TP+TN/TP+TN+FP+FN

\section{RESULTS}

The age of the study group ranged from 18-41 and was distributed as $20 \%$ of women less than 20 years old, $64 \%$ of women ranged from 20-30 years old and only $16 \%$ were more than 30 years old. The gestational age ranged from 18-22 weeks with a mean of 20 week.

In the current work, the 2D ultrasound detected no abnormality in 194 out of 200 fetuses [97.0\%], and 4 cases [2.0\%] had mega-cisterna magna, which were detected by the $4 \mathrm{D}$ and confirmed by postnatal transcranial ultrasound. in addition, $2 \mathrm{D}$ ultrasound detected 2 cases [1.0\%] who had encephalomylocele, that discovered and confirmed by $4 \mathrm{D}$ and postnatal transcranial US. On the other side, 2D ultrasound did not discover any case of Dandywalker malformation, but $4 \mathrm{D}$ US discovered 2 cases [1.0\%] that was confirmed by postnatal transcranial US. There was a complete agreement between prenatal $4 \mathrm{D}$ ultrasound and postnatal transcranial ultrasound [Table 1].

Using postnatal transcranial ultrasound as a reference standard, the prenatal 2D ultrasound had a sensitivity of $75.0 \%$, specificity of $100.0 \%$, PPV of $100.0 \%$, NPV of $98.7 \%$ and overall accuracy of $99.0 \%$. Otherwise, the prenatal $4 \mathrm{D}$ ultrasound was $100.0 \%$ sensitive and specific [Table 2]. 


\begin{tabular}{|c|c|c|c|}
\hline Detected anomaly & $\begin{array}{c}\text { 2D } \\
{[n=200]}\end{array}$ & $\begin{array}{c}\text { 4D } \\
{[n=200]}\end{array}$ & $\begin{array}{l}\text { Postnatal transcranial ultrasound } \\
\qquad[\mathrm{n}=200]\end{array}$ \\
\hline NAD & $194[97.0 \%]$ & $192[96.0 \%]$ & $192[96.0 \%]$ \\
\hline Mega-cisterna Magna & $4[2.0 \%]$ & $4[2.0 \%]$ & $4[2.0 \%]$ \\
\hline Encephalomylocele & $2[1.0 \%]$ & $2[1.0 \%]$ & $2[1.0 \%]$ \\
\hline Dandywalker malformation & - & $2[1.0 \%]$ & $2[1.0 \%]$ \\
\hline
\end{tabular}

Table [2]: Sensitivity and specificity of 2D and 4D for detection of fetal brain midline abnormalities using the postnatal transcranial ultrasound as a reference standard

\begin{tabular}{|c|c|c|}
\hline & Two-dimensional ultrasound & Four-dimensional ultrasound \\
\hline True positive [TP] & 6 & 8 \\
\hline False positive [FP] & 0 & 0 \\
\hline True negative [TN] & 192 & 192 \\
\hline False negative [FN] & 2 & 0 \\
\hline Sensitivity & $75.0 \%$ & $100.0 \%$ \\
\hline Specificity & $100.0 \%$ & $100.0 \%$ \\
\hline Positive predictive value [PPV] & $100.0 \%$ & $100.0 \%$ \\
\hline Negative predictive value [NPV] & $98.7 \%$ & $100.0 \%$ \\
\hline Overall accuracy & $99.0 \%$ & $100.0 \%$ \\
\hline
\end{tabular}

\section{DISCUSSION}

Fetal malformations are usually due to genetic aberrations. It could be stimulated by in-utero exposure to medications [e.g., tetracyclines and streptomycin], radiations, smoking and alcohol intake [19]. Currently, the two-dimensional ultrasound is routine prenatal screening method. However, it had certain limitations [e.g., artifacts and low image resolution] which reduce its diagnostic accuracy ${ }^{[20]}$. With technological advances, three- and fourdimensional ultrasound were introduced and played a supplementary role to $2 \mathrm{D}$ ultrasound, and could stand alone as an effective diagnostic tool [21].

In the current study, 2D revealed no abnormality among $97.0 \%$ of studied populations compared to $96 \%$ discovered by $4 \mathrm{D}$ ultrasound. The detected midline abnormalities were $3.0 \%$ and $4.0 \%$ by two and four-dimensional ultrasound, respectively. The detected anomalies by four-dimensional ultrasound were identical to the post-natal diagnosis by transcranial ultrasound. The reported incidence rate of midline cerebral abnormalities of fetal brain lies within the reported incidence in previous literature. For example, Milani et al. [6] reported that, fetal central nervous system [CNS] abnormalities are fairly common. The incidence rate ranges between 0.1 to $0.2 \%$ in live births and increased to $3-6 \%$ in stillbirths. In terms of frequency, the fetal CNS abnormalities comes after the cardiac abnormalities.

The prenatal ultrasound is a non-invasive, simple, readily available and cost-effective tool for prenatal screening. Thus, it could be an effective imaging modality for screening of fetal brain abnormalities, as reported by Onkar et al. [22] and Tutus et al. [23]. Gonçalves et al. [24] compared prenatal US with magnetic resonance imaging [MRI] and reported that, US was ablet to discover prenatal CNS abnormalities among $72.2 \%$ and had a specificity of $100.0 \%$. They concluded that, US is relatively accurate, safe and relatively cheap tool for prenatal screening of CNS malformation. However, they used the $2 \mathrm{D}$ and $3 \mathrm{D}$ ultrasound modalities.

Here, we go one step forward and included 4D ultrasound, and instead of prenatal MRI, we used postnatal transcranial ultrasound to minimize the fetal and maternal risk of radiation exposure. In addition, we performed our examination at the second trimester of pregnancy [18- 22 weeks of gestations] as recommended by obstetric guidelines of antenatal care to check fetal anatomy. At this time, the major and midline intracranial structures have formed and can be traced by sonographic visualization [6].

Wang et al. ${ }^{25]}$ used 2D and $4 \mathrm{D}$ to estimate the diagnostic value in fetal craniocerebral malformations. They reported that, the accuracy of $4 \mathrm{D}$ alone was significantly higher than 2D and combined approaches [2D plus 4D] accuracy was better than each modality alone. Both methods were identical to the actual diagnosis for $96.05 \%$ of all anomalies, while $4 \mathrm{D}$ was sensitive for $82.89 \%$ and 2 D sensitivity was $69.74 \%$. Of note, all patients included in their study were known to have an abnormality before screening and their evaluation was a retrospective in manner.

4D ultrasound can give real time multi-layered images as it scans the organ from multiple angles. Thus, the fetus's subtle structures, can be examined directly in a clear way. By 4D ultrasound, accurate differentiated diagnosis of different brain lesions could be achieved by the observation 
of the focal location, size and structure, the spatial relationship with surrounding parenchyma, as well as the stability of images with fetus movements [26].

In the current work, the 2D ultrasound failed to detect Dandywalker malformation. However, 4D could detect it and the diagnosis was confirmed to be correct by postnatal transcranial ultrasound. Correa et al. ${ }^{[2]]}$ described it as the commonest congenital cerebellar malformation, with cerebellar vermis hypoplasia or agenesis with posterior fossa enlargement, ventriculomegaly and dilation of fourth ventricle. These abnormalities could be detected by prenatal ultrasound. however, other abnormalities include cranial displacement of tentorium, torcula and lateral venous sinuses which could be seen by prenatal MRI. Bosemani et al. ${ }^{[28]}$ reported that the prenatal US of the posterior fossa is a challenging task from the technical point of view. The agenesis of vermis with cerebellar vermian remnant cephalad rotation is best seen in the sagittal plane. In the axial plane, an artifactual vermian cleft could be created by excessive steep angulation, leading to a false positive diagnosis. Additionally, there are other anomalies that can mimic cisterna magna dilatation [e.g., mega cisterna magna and posterior fossa arachnoid cyst].

Dandy-Walker malformation may be isolated or associated with other genetic aberrations and its prognosis depends largely on the degree of ventriculomegaly, that necessitates close follow up with prenatal US and postnatal MRI to predict the severity of neurodevelopmental delay [29]. In line with the current work, Glenn et al. [30] reported that, fetus with Dandy-Walker malformation could have a normal intellectual function, especially with normal lobulation of the vermis and no additional fetal brain abnormalities.

Early diagnosis of Dandy-Walker syndrome is useful for prediction of prognosis and for planning for delivery [29].

In the present study, the diagnosis of mega cisterna magna and encephalomylocele was done using $2 \mathrm{D}$ and $4 \mathrm{D}$ US. Hamisa et al. [31] found that giant cisterna magna was diagnosed in three cases using $2 \mathrm{D}$ and $4 \mathrm{D}$ US during the prenatal period and this was confirmed by postnatal MRI. As for encephalocele, prenatal 2D US detects approximately $80 \%$ of encephaloceles ${ }^{[32]}$. In another study, 4D US and MRI confirmed the diagnosis of encephalocele more than 2D [33].

This study showed that, the sensitivity of $4 \mathrm{D}$ versus $2 \mathrm{D}$ was $100 \%$ versus $75.0 \%$, the specificity and positive predictive value was $100 \%$ in $2 \mathrm{D}$ and $4 \mathrm{D}$ while the negative predictive value was $100 \%$ in $4 \mathrm{D}$ and $98.7 \%$ in $2 \mathrm{D}$ US. The accuracy of $4 \mathrm{D}$ was $100 \%$ in comparison with $99 \%$ for $2 \mathrm{D}$ US. In the study of Gonçalves et al. [34], fetuses were diagnosed by $2 \mathrm{D}$ ultrasonography showed an agreement with $3 D / 4 D$ in $90.4 \%$ of the findings. When compared to diagnoses performed after delivery, the sensitivity and specificity of 3D/4D ultrasonography was $92.2 \%$ and $76.4 \%$ respectively and 2D ultrasonography was $96.1 \%$ and $72.7 \%$ but there were no significantly different ${ }^{222]}$.

On the other side, Mittermayer et al. [35] reported that, although $2 \mathrm{D}$ and $4 \mathrm{D}$ US are able to detect many kinds of fetal brain malformation, some studies have shown that 2D and $4 \mathrm{D}$ ultrasound detection rates of fetal brain anomalies are only about $40-50 \%$.

The current work is unique in its prospective design, screening for malformations in whole cohort of pregnant females. However, one limiting step is the small number of included females in screening which yielded a low number of malformations. In addition, there are many challenges facing application of prenatal screening by ultrasound. These include maternal obesity, fetal position, reverberation antifiction and oligohydramnios which could limit the ability of US and reduce resolution of its images. The early ossification of fetal skull represents another challenge [36, 37]. Therefore, magnetic resonance imaging [MRI] has come into practice, with its advantages of better soft tissue contrast resolution, larger field of view and opportunity to obtain multiplane images make fetal MRI an important diagnostic tool [38].

On the other side, the quality of MRI images may be negatively affected by the movement of the fetus during the scan, which may limit MRI diagnostic accuracy in some cases. Hence, ultrafast MRI have been introduced to reduce

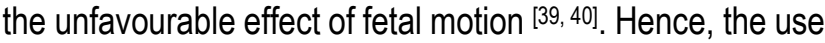
of $4 \mathrm{D}$ ultrasound which consider fetal movement as the ultrafast MRI and was free from high cost and radiation risk exposure, which adds to the value of the current study.

We could conclude that, the 2D ultrasound still have its role in the diagnosis of fetal brain midline abnormalities. The 4D ultrasound showed superiority in diagnosis and confirmation of the midline structure abnormalities, and it was in complete correlation with the diagnosis of postnatal transcranial US. However, further evaluation of the accuracy and efficiency of 4D in diagnosis of midline structure anomalies should be investigated in large population studies.

Financial and non-financial relationships and Activities of Interest

None 


\section{REFERENCES}

1. Hoekzema E, Barba-Müller E, Pozzobon C, Picado M, Lucco F, García-García D, Soliva JC, Tobeña A, Desco M, Crone EA, Ballesteros A, Carmona S, Vilarroya O. Pregnancy leads to long-lasting changes in human brain structure. Nat Neurosci. 2017;20[2]:287-296. doi: 10.1038/nn.4458.

2. Cloutier M, Gallagher L, Goldsmith C, Akiki S, Barrowman N, Morrison S. Group genetic counseling: An alternate service delivery model in a high-risk prenatal screening population. Prenat Diagn. 2017 Nov;37[11]:1112-1119. doi: 10.1002/pd.5149.

3. Elshazzly M, Lopez MJ, Reddy V, Caban O. Embryology, Central Nervous System. 2021 Apr 10. In: StatPearls [Internet]. Treasure Island [FL]: StatPearls Publishing; 2021 Jan-. PMID: 30252280.

4. Salomon LJ, Alfirevic Z, Bilardo CM, Chalouhi GE, Ghi T, Kagan KO, Lau TK, Papageorghiou AT, Raine-Fenning NJ, Stirnemann J, Suresh S, Tabor A, Timor-Tritsch IE, Toi A, Yeo G. ISUOG practice guidelines: performance of first-trimester fetal ultrasound scan. Ultrasound Obstet Gynecol. 2013 Jan;41[1]:102-13. doi: 10.1002/uog.12342.

5. Katorza E, Bertucci E, Perlman S, Taschini S, Ber R, Gilboa Y, Mazza V, Achiron R. Development of the Fetal Vermis: New Biometry Reference Data and Comparison of 3 Diagnostic Modalities-3D Ultrasound, 2D Ultrasound, and MR Imaging. AJNR Am J Neuroradiol. 2016 Jul;37 [7]: 1359-66. doi: 10.3174/ajnr.A4725.

6. Milani HJF, Barreto EQS, Araujo Júnior E, Peixoto $A B$, Nardozza LMM, Moron AF. Ultrasonographic evaluation of the fetal central nervous system: review of guidelines. Radiol Bras. 2019 May-Jun; 52 [3]:176-181. doi: 10.1590/0100-3984.2018.0056.

7. Mandel AM. Diagnosis and management of congenital neurologic disease during pregnancy. Handb Clin Neurol. 2020; 171:291-311. doi: 10.1016/B978-0-444-642394.00015-1.

8. Rewane A, Munakomi S. Embryology, Central Nervous System, Malformations. 2021 Mar 6. In: StatPearls [Internet]. Treasure Island [FL]: StatPearls Publishing; 2021 Jan-. PMID: 31985964.

9. Muresan D, Popa R, Stamatian F, Rotar IC. The use of modern ultrasound tridimensional techniques for the evaluation of fetal cerebral midline structures- a practical approach. Med Ultrason. 2015 Jun;17[2]:235-40. doi: 10.11152/ mu.2013.2066.172.dm1.

10. Comănescu AC, Cernea N, Tica OS, Comănescu MV, Niculescu EC, Florou C, Grosu F. Sonographic evaluation of fetal cerebral structures correlated with histological aspects. Rom J Morphol Embryol. 2015;56[2]:393-400. PMID: 26193204

11. Renna MD, Pisani $P$, Conversano F, Perrone E, Casciaro E, Renzo GC, Paola MD, Perrone A, Casciaro S. Sonographic markers for early diagnosis of fetal malformations. World J Radiol. 2013 Oct 28; 5[10]:356-71. doi: 10.4329/wjr.v5.i10.356.

12. Eyüboğlu İ, Dinç G. Fetal US and MRI in detection of craniospinal anomalies with postnatal correlation: singlecenter experience. Turk J Med Sci. 2021 Jun 28;51[3]:1211-1219. doi: 10.3906/sag-2011-122.

13. lliescu D, Tudorache $S$, Comanescu A, Antsaklis $P$, Cotarcea $\mathrm{S}$, Novac L, Cernea N, Antsaklis A. Improved detection rate of structural abnormalities in the first trimester using an extended examination protocol. Ultrasound Obstet Gynecol. 2013 Sep;42[3]:300-9. doi: 10.1002/uog. 12489.

14. Visentin A, Pilu G, Falco P, Bovicelli L. The transfrontal view: a new approach to the visualization of the fetal midline cerebral structures. J Ultrasound Med. $2001 \mathrm{Apr} ; 20[4]$ : 329-33. doi: 10.7863/ jum.2001.20.4.329.

15. Grigore M, Gafitanu D, Socolov D, Grigore A, Nemeti G, Micu $R$. The role of 4D US in evaluation of fetal movements and facial expressions and their relationship with fetal neurobehaviour. Med Ultrason. 2018 Feb 4;1[1]:88-94. doi: $10.11152 / \mathrm{mu}-1350$.

16. Moreira Neto R, Porovic S. Clinical study of fetal neurobehavior by the KANET test. J Perinat Med. 2018 Aug 28;46[6]:631-639. doi: 10.1515/jpm-2016-0414.

17. Öcal DF, Nas T, Güler I. The place of four-dimensional ultrasound in evaluating fetal anomalies. Ir J Med Sci. 2015;184[3]:607-12. doi: 10.1007/s11845-014-1184-2.

18. Muresan D, Popa R, Stamatian F, Rotar IC. The use of modern ultrasound tridimensional techniques for the evaluation of fetal cerebral midline structures- a practical approach. Med Ultrason. 2015 Jun;17[2]:235-40. doi: 10.11152/mu.2013.2066.172.dm1.

19. Varcin KJ, Jeste SS. The emergence of autism spectrum disorder: insights gained from studies of brain and behaviour in high-risk infants. Curr Opin Psychiatry. 2017 Mar;30[2]:85-91. doi: 10.1097/YC0.0000000000000312.

20. Kurian J, Sotardi S, Liszewski MC, Gomes WA, Hoffman T, Taragin $\mathrm{BH}$. Three-dimensional ultrasound of the neonatal brain: technical approach and spectrum of disease. Pediatr Radiol. 2017 May;47[5]:613-627. doi: 10.1007/ s00247-016-3753-1.

21. Barisic LS, Stanojevic M, Kurjak A, Porovic S, Gaber G. Diagnosis of fetal syndromes by three- and four- 
dimensional ultrasound: is there any improvement? J Perinat Med. 2017 Aug 28;45[6]: 651-665. doi: 10.1515/ jpm-2016-0416.

22. Onkar $D$, Onkar $P$, Mitra K. Evaluation of Fetal Central Nervous System Anomalies by Ultrasound and Its Anatomical Co-relation. J Clin Diagn Res. 2014 Jun;8[6]:AC05-7. doi: 10.7860/JCDR/ 2014/8052.4437.

23. Tutus S, Ozyurt S, Yilmaz E, Acmaz G, Akin MA. Evaluation and prevalence of major central nervous system malformations: a retrospective study. North Clin Istanb. 2014 Dec 8;1[2]:78-83. doi: 10.14744/nci.2014.84803.

24. Gonçalves LF, Lee W, Mody S, Shetty A, Sangi-Haghpeykar $H$, Romero R. Diagnostic accuracy of ultrasonography and magnetic resonance imaging for the detection of fetal anomalies: a blinded case-control study. Ultrasound Obstet Gynecol. 2016 Aug;48[2]:185-92. doi: 10.1002/ uog. 15774 .

25. Wang $Y$, Chen X, Zhong S, Zhang R, Pan Y, An P, Gao X. Diagnostic Value of Two-Dimensional plus FourDimensional Ultrasonography in Fetal Craniocerebral Anomalies. Iran J Public Health. 2019 Feb;48[2]:323-330. PMID: 31205887.

26. Benzie RJ, Starcevic V, Viswasam K, Kennedy NJ, Mein BJ, Wye DA, Martin A. Effect of three- vs four-dimensional ultrasonography on maternal attachment. Ultrasound Obstet Gynecol. 2018 Apr;51[4]:558-559. doi: 10.1002/ uog. 17567.

27. Correa GG, Amaral LF, Vedolin LM. Neuroimaging of DandyWalker malformation: new concepts. Top Magn Reson Imaging. 2011 Dec;22[6]:303-12. doi: 10.1097/RMR. 0b013e3182a2ca77.

28. Bosemani T, Orman G, Boltshauser E, Tekes A, Huisman TA, Poretti A. Congenital abnormalities of the posterior fossa. Radiographics. 2015 Jan-Feb;35[1]:200-20. doi: 10.1148/ rg.351140038.

29. Di Mascio D, Sileo FG, Khalil A, Rizzo G, Persico N, Brunelli R, Giancotti A, Panici PB, Acharya G, D'Antonio F. Role of magnetic resonance imaging in fetuses with mild or moderate ventriculomegaly in the era of fetal neurosonography: systematic review and meta-analysis. Ultrasound Obstet Gynecol. 2019 Aug; 54[2]:164-171. doi: 10.1002/uog.20197.

30. Glenn OA, Cuneo AA, Barkovich AJ, Hashemi Z, Bartha Al, Xu D. Malformations of cortical development: diagnostic accuracy of fetal MR imaging. Radiology. 2012 Jun;263 [3]: 843-55. doi: 10.1148/radiol.12102492.

31. Hamisa M, Dabees N, Ataalla WM, Ziada DH. Magnetic resonance imaging versus Ultrasound examination in detection of prenatal fetal brain anomalies. Egypt J Radiol Nuclear Med. 2013; 44 [3]: 665-672. DOI: 10.1016/ j.ejrnm.2013.05.004.

32. Borowski $D$, Wegrzyn $P$, Bartkowiak $R$, Wyrwas $D$, Wielgoś M. [First trimester diagnosis of encephalocele--report of two cases and review of the literature]. Ginekol Pol. 2011 Sep; 82 [9]:700-4. Polish [Englsih Abstract]. PMID: 22379932.

33. Kehila M, Ghades S, Abouda HS, Masmoudi A, Chanoufi MB. Antenatal Diagnosis of a Rare Neural Tube Defect: Sincipital Encephalocele. Case Rep Obstet Gynecol. 2015; 2015:613985. doi: 10.1155/2015/613985.

34. Gonçalves LF, Nien JK, Espinoza J, Kusanovic JP, Lee W, Swope B, Soto E, Treadwell MC, Romero R. What does 2-dimensional imaging add to 3- and 4-dimensional obstetric ultrasonography? J Ultrasound Med. 2006 Jun; 25 [6]:691-9. doi: 10.7863/jum.2006.25.6.691.

35. Mittermayer C, Blaicher W, Brugger PC, Bernaschek G, Lee A. Foetal facial clefts: prenatal evaluation of lip and primary palate by $2 \mathrm{D}$ and $3 \mathrm{D}$ ultrasound. Ultraschall Med. 2004 Apr;25[2]:120-5. doi: 10.1055/s-2004-813102.

36. Rossi AC, Prefumo F. Additional value of fetal magnetic resonance imaging in the prenatal diagnosis of central nervous system anomalies: a systematic review of the literature. Ultrasound Obstet Gynecol. 2014 Oct;44[4]: 388-93. doi: 10.1002/uog.13429.

37. Sefidbakht S, Dehghani S, Safari M, Vafaei H, Kasraeian M. Fetal Central Nervous System Anomalies Detected by Magnetic Resonance Imaging: A Two-Year Experience. Iran J Pediatr. 2016 Jun 6;26[4]: e4589. doi: 10.5812 lijp.4589.

38. Masselli G, Vaccaro Notte MR, Zacharzewska-Gondek A, Laghi $F$, Manganaro L, Brunelli R. Fetal MRI of CNS abnormalities. Clin Radiol. 2020 Aug;75[8]: 640.e1-640. e11. doi: 10.1016/j.crad. 2020.03.035.

39. Martin T, Janzen C, Li X, Del Rosario I, Chanlaw T, Choi S, Armstrong T, Masamed R, Wu HH, Devaskar SU, Sung K. Characterization of Uterine Motion in Early Gestation Using MRI-Based Motion Tracking. Diagnostics [Basel]. 2020;10[10]:840. doi: 10.3390/diagnostics 10100840.

40. Manganaro L, Bernardo S, Antonelli A, Vinci V, Saldari M, Catalano C. Fetal MRI of the central nervous system: State-of-the-art. Eur J Radiol. 2017 Aug; 93:273-283. doi: 10.1016/j.ejrad. 2017.06.004. 


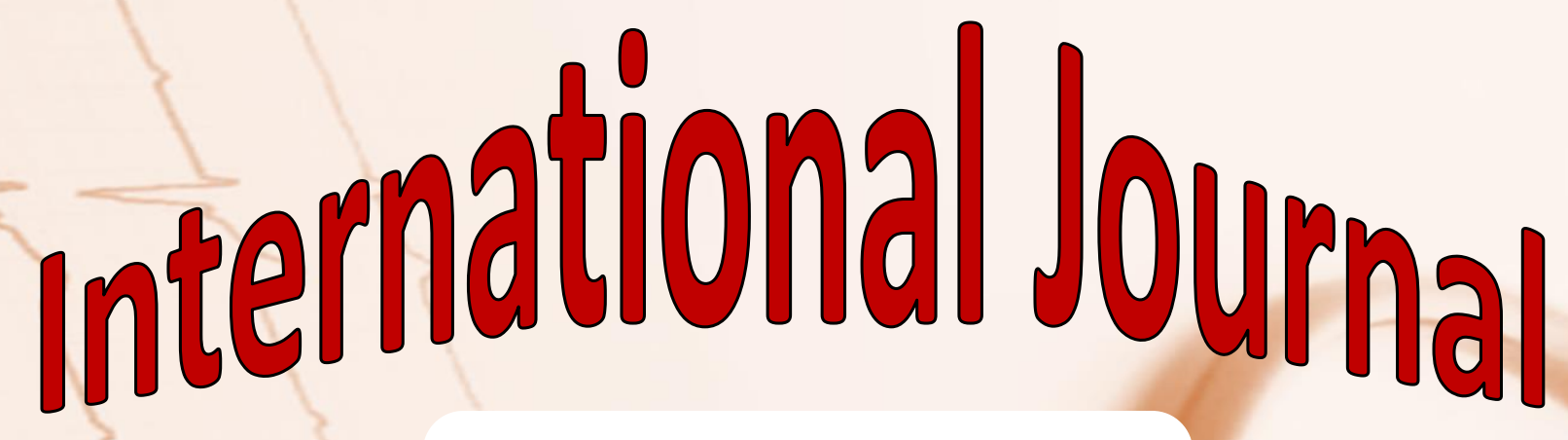

https://ijma.journals.ekb.eg/ Print ISSN: 2636-4174 Online ISSN: 2682-3780

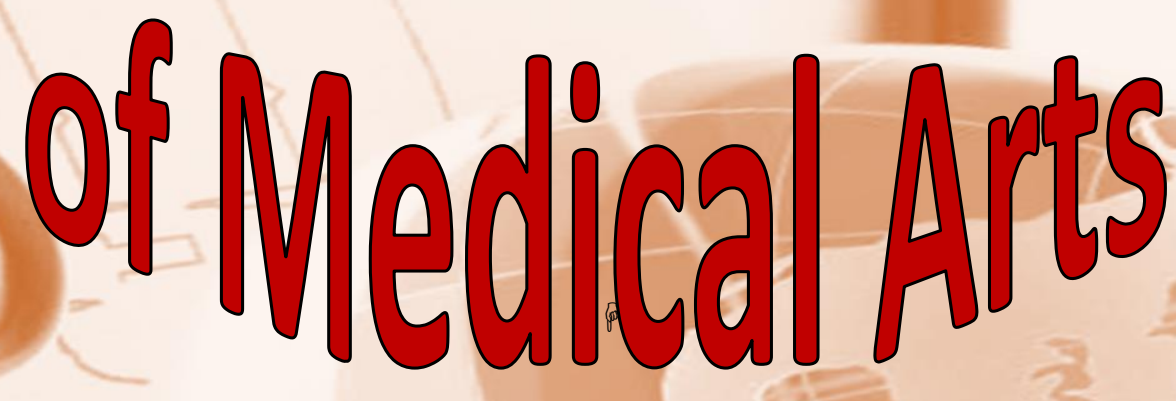

